\title{
Psycho-Analytical Investigation of Stress among Students of Higher Technical Education in India: A Case Study
}

\author{
Mr. Sandeep Kumar Sharma ${ }^{1}$, Dr. Sweta Sinha ${ }^{2}$
}

\section{ABSTRACT}

Academic period is the best phase of life for many students where they try to shape themselves in a perfect frame under the supervision of their teachers. But sometimes many students are unable to compensate the need of the actual goal setting. Somehow they also get deviated from their path due to the lack of proper setting with the situation as well as internal and external factors that imposes unwilling pressure on them. Stress appears when the complexity of internal and external factor exceeds individual's resources to cope with their situation. It is critically determined by the name of depression, anxiety, stress, as well as phobia. Students frequently encounter stressors which may test their capability to cope: conforming to recent environment, managing a massive work load, making new friends, becoming more independent and dealing with several issues. From a closer outlook, students' confront various challenges in their everyday life therefore the whole idea of an exciting and vibrant academic life is veiled by these challenges which leads to stress. If not dealt with, it can only escalate and hamper academic performance as well as emotional and social well-being. In the past ten years the percentage of suicide has increased considerably among the educated class in comparison to the uneducated sections of the Indian society. Among the educated section, the prime suicide prone people belong to educational level raging from higher secondary to graduation and above as survey by National Crime Records Bureau (NCRB, India, See Annexure-I). This provides the chief motivation to carry out the psychoanalytical study of students. The current study examines the level of stress and its major causative agents among the $\mathrm{PhD}$ (Doctor of Philosophy) students of a prestigious technical institute of India. The primary aim of term paper is to assess the level of stress and its major triggering factors among the PhD students. The methodology for the present paper is based on a quantitative approach where a questionnaire survey was conducted to collect data with a sample size of 30 students.

Keywords: Stress, Depression, Anxiety, Performance, Psycholinguistic, Suicide

\footnotetext{
${ }^{1}$ Research Scholar, Dept. of Humanities and Social Sciences, Indian Institute of Technology Patna, India

${ }^{2}$ Assistant Professor, Dept. of Humanities and Social Sciences, Indian Institute of Technology Patna, India *Responding Author

Received: February 14, 2017; Revision Received: March 9, 2017; Accepted: March 10, 2017
}

(C) 2017 Sharma S, Sinha S; licensee IJIP. This is an Open Access Research distributed under the terms of the Creative Commons Attribution License (www.creativecommons.org/licenses/by/2.0), which permits unrestricted use, distribution, and reproduction in any Medium, provided the original work is properly cited. 


\section{Psycho-Analytical Investigation of Stress among Students of Higher Technical Education in India: A Case Study}

Several students experience stress when they try to settle in busy environment of educational and social stage; or professional and personal settings in life. Stress appears in different phase of life because of unwilling psychological and social factors. A physical response is stimulated due to stress and it easily ruins the memory of an individual which may cause further mental retort or delinquency. An individual's life is subjected to several stressors determined as academic pressure with a commitment of success, uncertainty of future goal settings and difficulties in anticipation of excellence in educational system. Students face social, emotional and physical and family problems which may affect their learning potential and academic representation (Fish and Nies, 1996; Chew-Graham et al., 2003). The level of stress among the students of higher education is higher than other stages of life (Kumar and Bhukar 2013). In addition, it is observed that students of higher education have an elevated inclination toward the felling despondency sometime during their educational period academic environment (David, 2009). Apart from personal and social problems there are several other physical impairments that are somehow related to the academic life of an individual. It depends on the particular circumstances with respect to research facility, departmental behavior, and relationship with the supervisor, and also failure to achieve the research goal setting during the crucial period of doctoral work. If circumstances are not smooth it might lead to stress. The stress level varies from student to student in accordance with their personal, social and academic environments. Therefore the research students experience disorders such as stress from a variety of different sources and it depends on positive and negative perspective which makes them different from others in the same environment.

\section{LITERATURE REVIEW}

At present stress has gripped the modern world viciously and has become an anonymous fellow of human life. Pinel (2003) stated stress as a physiological response to perceived threat. Thus playing a role of negative effecter on human life in the form of unwilling pressures and events (Benson and Stuart, 1992) and can generally be observed as a setting of neurological and physiological reactions that serve as a pliant function (Franken, 1994). Holmes and Rahe (1967) pointed out that the changes in life that entails several reacclimate can be observed as stressful situation. Stress reflects the physical reaction to refine that needs a physical, mental or emotional adjustment or response. High level of the stress is nearly to affect the health of the students (Elizabeth, 2003). Lazarus \& Folkman (1984) state that stress is a mental or physical occurrence organized through an individual's cognitive assessment of the incentive and result of his communication in a particular domain. The existence of stress is determined according to the extent of the stress triggering factors. Stressor can be anything that challenges one's compliance or stimulate an individual's body or mental perception (Feng, 1992; Volpe 2000). Stress occurs due to the various factors where it can be negative or positive to an individual depending on the basis of strength and perseverance of the stress, personality of an individual, cognitive evaluation 


\section{Psycho-Analytical Investigation of Stress among Students of Higher Technical Education in India: A Case Study}

of the stress and support of the social phenomena. The sources of stress are summarized as follows:

\section{Physical Factor}

Mostly adolescents are distressed due to their physical façade more than other constituents. Most of them are constantly disappointed because of their physical impression (Siegel and Lane, 1982). Wang and Ko (1999) stated that girls are troubled more than boys, commonly due to their physical appearance. The observance of girls about their own perspective is ill-favored and they experience negative self- impression. The symptoms like migraine were signs of mental overburden. While some other indication included exhaustion, sadness, anxiety, disappointment with certain mutual relationship, change in sleeping habit, and a radical up and down in the body weight. It is mentioned that high goal settings, being idealist and differentiate own with some others and self-humiliation may the reason of stress and result to be in depression (Feng, 1992).

\section{Family Factor}

Conflicting families are designated by a lack of conversation between parent and child and the mutual comprehension of expectations between each other (Liu and Chen, 1997). Totalitarian families hardly express their concern about their children. Whatever the control or punishment are imposed only strengthen the psychological pressure on their children.

\section{Academic Factor}

It is proposed that academic place is one of the primary roots of stress among teenagers (Chiang, 1995). This kind of stress occurs due to the burden of academic workload, undesirable performance, preparation for academic tests, lack of interest in a particular subject and punishment. Mostly, parents are anxious about their children's academic performance, achievement and moral conduct. The expectation of the parents from their children is not only to respect others and follow moral norms but also become elite in the future (Liu and Chen, 1997). It is said that education is the perfect goal settings of an individual's life. However, people use academic performance and achievement as the specific criteria for evaluating an individual's performance at any educational hub. This kind of norm sets dual stress on students. Stress occurs due to high expectations of well-wishers just anguish for an individual (Cheng, 1999).

\section{Kinship Factor}

Most of the people are desperate to develop a relationship with the opposite sex. As there is no absolute strategy for making friendship with the opposite sex most of them usually do not have the experience of conducting in such situation. Excluding teenage students who often suffer from stress induced by a sense of diffidence when they are dating someone. They are always worried that they might lose their relationships and their friends and family might think negatively of 


\section{Psycho-Analytical Investigation of Stress among Students of Higher Technical Education in India: A Case Study}

their relationship. Therefore to develop a heterosexual relationship is always a challenge and also a stressor for an individual (Wang and Ko, 1999).

\section{Social factor}

With the development of human civilization and increasing diversity of the society people required to play more roles. In the workplace, subordinate candidate, a supervisor, a manager, an associate to other employees, a member of an organization or a leader; at home people need to be the wife or husband, mother or father and daughter or son. Even in the time of amusement, people may need to be a friend to others. Therefore, stress is extensive in modern life. Formation of stress is highly associated with the social domain. Stress appears not only in a complex and competitive environment but also in a monotonous and stimulus-less domain (Feng, 1992).

\section{RESEARCH METHODOLOGY}

The methodology of the present paper was based on assessing the stress level among the $\mathrm{PhD}$ students of Indian Institute of Technology Patna a premier technical institute in India. The study of the present work was followed by a quantitative approach where a questionnaire survey was conducted to collect data. Other secondary sources such as book, research article etc. were consulted to prepare theoretical framework of the research paper. A questionnaire consisting of 35 questions (see annexure I) was used to point out stress responses among $30 \mathrm{PhD}$ (15 Female, 15 Male) students in the age group of 25 to 30 years. The data was analyzed on the basis of four responses "sometimes, often, always and never" for different factors such as "academic, personal, social and others" for male and female respondents. The calculated total responses are 525 for 35 questions categorized gender wise in sample size of 30 where first one is observation of stress responses among $\mathrm{PhD}$ students and second one refers to the major triggering factor of stress. Further analysis points out three major responses that were categorized as prone to stress, under stress and never stress. The next observation refers to the percentage of responses in prone to stress, under stress and never stress categories at the individual level. The last analysis focuses on total percentage of responses that come under prone to stress, under stress and never stress categories among male and female students for the major stressor.

\section{DATA ANALYSIS AND RESULT}

The data analysis was processed through distinct steps where first step pointed out the total responses of stress among $\mathrm{PhD}$ students in favor of sometimes, often, always and never so that the positive and negative stress responses scaled among them, as represented in figure below. 


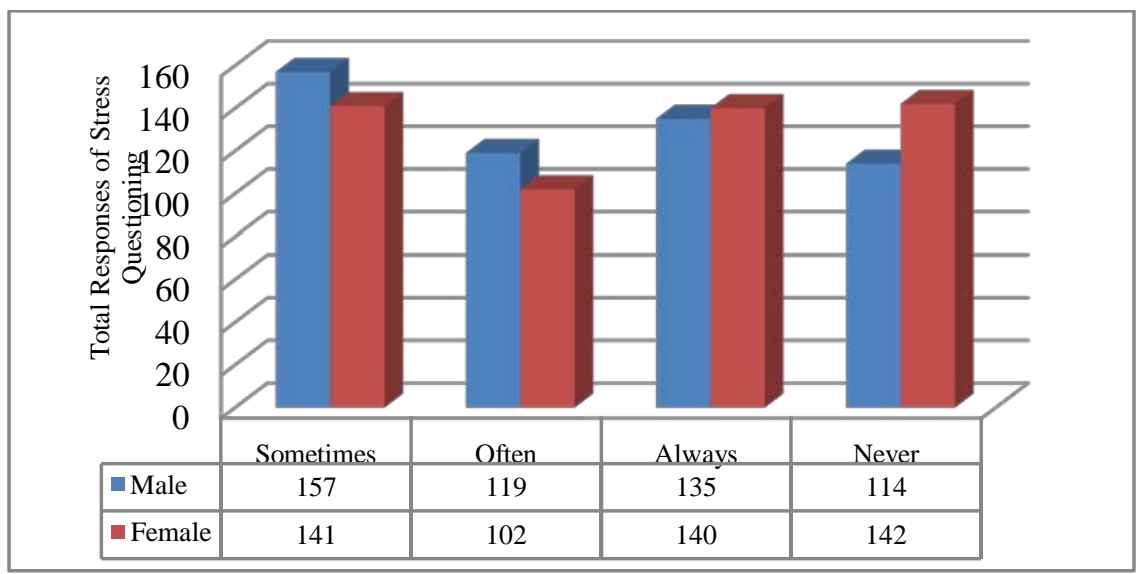

Figure1. Stress Responses among PhD Students

The further analysis was conducted to get major triggering factor of stress among the students where basic triggering factor was noticed as academic, personal, social, and others that affect an individual's life unwillingly. The processes of the data observation distributed on the basis of male and female candidate and counted their responses of stress according to set of questionnaire in favor of sometimes, often, always and never in terms of major stress factors such as academic, personal, social and others as in the following figure.

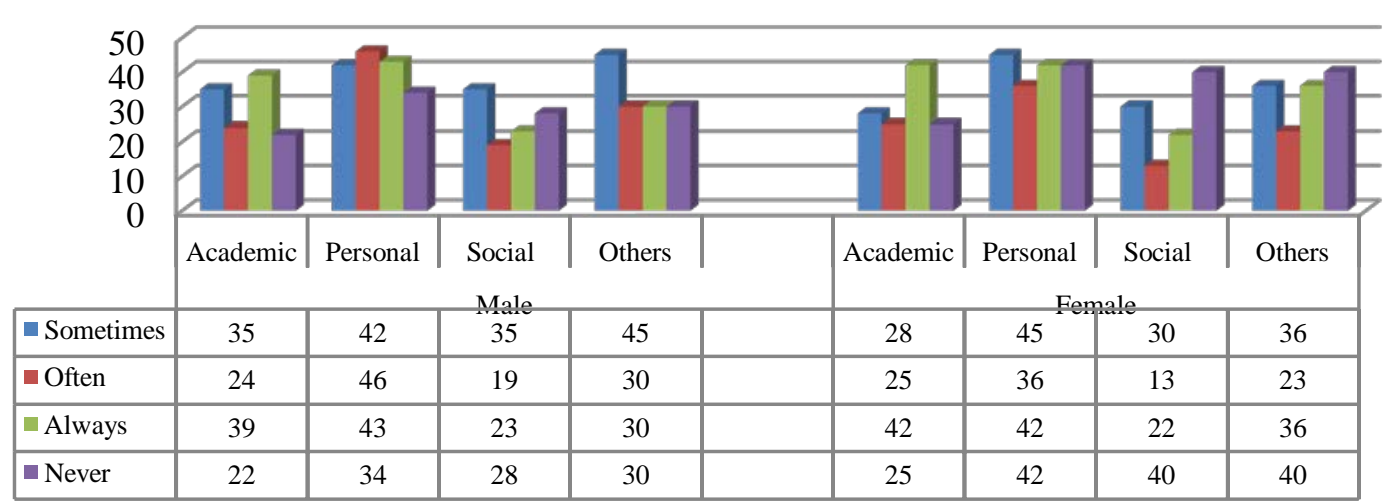

Figure2. Major Factors of Stress among PhD Students

After the observation total 525 responses were noticed to major triggering factors of stress among male and female students in each group on the basis of 35 questions (15 x $35=525$ Male and $15 \times 35$ Female). The total responses of male and female students were divided into three sections as 'prone to stress, under stress and never stress' in terms of major triggering factor of stress that categorized as academic, personal, social and others. There are four responses like sometimes, often, always and never that underlying on each category separately. The four responses managed into three sections as sometimes underlying in prone to stress, often, always in under stress and never in section of never stress. Having 'sometimes' in prone to stress because there is no certainty that a person has longer effect of stress it can be frequent or for a certain period of time after that he gets free from this unwilling pressure. To be 'often and always' in the section of under stress is a valid clue because an individual can be stressed in both

(c) The International Journal of Indian Psychology, ISSN 2348-5396 (e)| ISSN: 2349-3429 (p) | 141 


\section{Psycho-Analytical Investigation of Stress among Students of Higher Technical Education in India: A Case Study}

condition for a long period of time and except of these two section other managed into never stress according to each category as shown in the table.

Table 1- Distribution of Responses

\begin{tabular}{|c|c|c|c|c|c|}
\hline Gender & Category & Prone to stress & \multicolumn{2}{|c|}{ Under stress } & Never Stress \\
\hline \multirow{5}{*}{ Male } & & Sometimes & Often & Always & Never \\
\hline & Academic & 35 & 24 & 39 & 22 \\
\hline & Personal & 42 & 46 & 43 & 34 \\
\hline & Social & 35 & 19 & 23 & 28 \\
\hline & Others & 45 & 30 & 30 & 30 \\
\hline \multirow{4}{*}{ Female } & Academir & 28 & 55 & 12 & 25 \\
\hline & Personal & 45 & 36 & 42 & 42 \\
\hline & Social & 30 & 13 & 22 & 40 \\
\hline & Others & 36 & 23 & 36 & 40 \\
\hline
\end{tabular}

In the further analysis response often and always was added to section under stress that has usual phenomena to be in stress than other section and counted responses of each category among 525 responses as shown in the following table.

Table 2- Section wise distribution of stress response

\begin{tabular}{|c|c|c|c|c|c|}
\hline Gender & Category & Prone to stress & Under stress & Never stress & Total Response \\
\hline \multirow{4}{*}{ Male } & Academic & 35 & 63 & 22 & 120 \\
\hline & Personal & 42 & 89 & 34 & 165 \\
\hline & Social & 35 & 42 & 28 & 105 \\
\hline & Others & 45 & 60 & 30 & 135 \\
\hline \multirow{6}{*}{ Female } & & & & Total & 525 \\
\hline & Academic & 28 & 67 & 25 & 120 \\
\hline & Personal & 45 & 78 & 42 & 165 \\
\hline & Social & 30 & 35 & 40 & 105 \\
\hline & Others & 36 & 59 & 40 & 135 \\
\hline & & & & Total & 525 \\
\hline
\end{tabular}

After the categorical distribution of stress responses data was analyzed to get percentage of triggering factors of stress responses according to three distinct sections prone to stress, under stress and never stress. Each category of stress factor was analyzed in terms of three sections and noticed the percentage of each one on the basis of stress responses among male and female students separately as represented in the table below.

(c) The International Journal of Indian Psychology, ISSN 2348-5396 (e)| ISSN: 2349-3429 (p) | 142 


\section{Psycho-Analytical Investigation of Stress among Students of Higher Technical Education in India: A Case Study}

Table 3- Category wise Percentage of stress responses

\begin{tabular}{|c|l|c|c|c|}
\hline Gender & \multicolumn{1}{|c|}{ Category } & Prone to stress & Under stress & Never stress \\
\hline \multirow{4}{*}{ Male } & & $\mathbf{\%}$ & $\mathbf{\%}$ & $\mathbf{\%}$ \\
\cline { 2 - 5 } & Academic & 29.16 & 52.5 & 18.33 \\
\cline { 2 - 5 } & Personal & 25.45 & 53.93 & 20.60 \\
\cline { 2 - 5 } & Social & 33.33 & 40.00 & 26.66 \\
\cline { 2 - 5 } & Others & 33.33 & 44.44 & 22.22 \\
\hline \multirow{4}{*}{ Female } & & & & \\
\cline { 2 - 5 } & Academic & 23.33 & 55.83 & 20.83 \\
\cline { 2 - 5 } & Personal & 27.27 & 47.27 & 25.45 \\
\cline { 2 - 5 } & Social & 28.57 & 33.33 & 29.09 \\
\cline { 2 - 5 } & Others & 26.66 & 43.70 & \\
\hline
\end{tabular}

The above description was represented total percentage of response based on three stress sections prone to stress, under stress and never stress according to category of major stress factor in terms of male and female students. After the observation of total responses in each section again data was processed through to get total percentage of responses of stress factor in terms of three sections prone to stress, under stress and never stress in male and female students as represented in the following table.

Table-4 Section wise total percentage of stress responses

\begin{tabular}{|c|c|c|c|}
\hline \multirow{4}{*}{ Male } & Section 1 & Section 2 & Section 3 \\
\cline { 2 - 4 } & Prone to Stress & Under stress & Never Stress \\
\cline { 2 - 4 } & 157 & 254 & 114 \\
\cline { 2 - 4 } Female & $29.90 \%$ & $48.38 \%$ & $21.71 \%$ \\
\cline { 2 - 4 } & Prone to Stress & Under stress & Never Stress \\
\cline { 2 - 4 } & 139 & 239 & 147 \\
\hline
\end{tabular}

In the above description the survey was based on stress responses among $30 \mathrm{PhD}$ students (15 male and 15 female) in terms of a set of questionnaire consisting 35 questions. Total 525 responses were noticed from each group (525- male and 525- female). From 525 responses 48.38\% in under stress, $29.90 \%$ in prone to stress and $21.71 \%$ in never stress were noticed in male group while $45.52 \%$ in under stress, $26.47 \%$ prone to stress and $28.00 \%$ in female group. In terms of academic level 55.83\% responses were noticed in female group while $52.5 \%$ in male group in under stress. At the personal level 53.93\% responses were noticed in male group under stress while $47.27 \%$ in female. In social category $40 \%$ responses were noticed in under stress for male group while $33.33 \%$ for female group and in others responses for male and female group was $44.44 \%$ and $43.70 \%$ respectively. In favor of prone to stress responses were noticed according to category wise in male group as academic $29.16 \%$, personal $25.45 \%$, social $33.33 \%$ and others $33.33 \%$ while in female group as academic $23.33 \%$, personal $27.27 \%$, social $28.57 \%$

(c) The International Journal of Indian Psychology, ISSN 2348-5396 (e)| ISSN: 2349-3429 (p) | 143 


\section{Psycho-Analytical Investigation of Stress among Students of Higher Technical Education in India: A Case Study}

and others $26.66 \%$ responses were noticed. On the basis of total responses in both section under stress and prone to stress it was observed that male students are more stressed or prone to stressed than female students.

\section{CONCLUSION}

The overview of the study says that $\mathrm{PhD}$ students are exposed to stress due to distinct triggering factors as academic, personal, social and others from their surroundings. The reason behind the stress level may or may not be limited to these factors. It can result from trivial to large problems in the life of an individual in relation to present, past and future perspective. According to above analysis $48.38 \%$ male and $45.52 \%$ female students have positive response to be in under stress whereas $29.90 \%$ male and $26.47 \%$ students are prone to stress due to major triggering factors including all as academic, social, personal and others. Academic, personal, social problems all play an important role in the development of stress. The investigation points out that academic and personal factor are the most affective stressor than social or any other. Several academic, personal and social problems are unwillingly stuck on individual's life and deviates him from his motives of life and changes his psychological perception about the existing environment, society, and the world. A lot of researches and remedial action are focused on improving the academic environment at junior and sub junior levels of school and college. Effective stress management workshop and training must be designed for the students engaged in pursuing high degrees more so in developing countries like India where resources for facilitating quality research is scarce.

\section{Acknowledgments}

The author appreciates all those who participated in the study and helped to facilitate the research process.

Conflict of Interests: The author declared no conflict of interests.

\section{REFERENCES}

Benson H, Stuart EL (1992). The Wellness Book: The comprehensive guide to maintaining health and treating stress-related illness. New York: Carol Publishing Group.

Cheng, C. S. (1999). Life Stress of and Guidance for Adolescents. Taipei: Psychological Publishing Co., Ltd.

Chew-Graham, C.A., Rogers, A., \& Yassin, N. (2003) "I would not want it on my CV or their records": Medical students' experiences of help seeking for mental health problems. Medical Education.

Chiang, C. X. (1995). A Study of Stress Reactions among Adolescents. Chinese Journal of School Health

David M (2009). Student life independent newspaper. Washington University in St Louis.

Elizabeth V (2003). Concern over high stress levels among students. The Hindi 


\section{Psycho-Analytical Investigation of Stress among Students of Higher Technical Education in India: A Case Study}

Feng, G. F. (1992). Management of Stress and Loss. Taipei: Psychological Publishing Co., Ltd. Fish C, Nies MA (1996). Health promotion needs of students in a college environment. Public Health Nurs.

Franken RE (1994). Human Motivation. Belmont, CA: Brooks/Cole Publishing Company. Holmes TH, Rahe RH (1967). The social readjustment rating scale. J. Psychosom.

Kumar, S., \& Bhukar, J. P. (2013). Stress level and coping strategies of college students. Journal of Physical Education and Sport Management, 4(1), 5-11.

Lazarus, R. S., and Folkman, S. (1984). Stress, Appraisal, and Coping. New York: Springer.

Liu, A. Y., and Chen, Y. H. (1997). Adolescent Psychology. Taipei: Sanmin Books.

Pinel JPT (2003). Biopsychology. United States of America: Allyn and Bacon.

Siegel, L., and Lane, I. M. (1982). Personnel and Organizational Psychology. Homewood, Volpe, J. F. (2000). A guide to effective stress management. Career and Technical Education Wang, H. C. and Ko, H. W. (1999). Adolescent Psychology. Taipei: Psychological Publishing Co., Ltd.

\section{ANNEXURE I}

Table .1 Percentages of Suicide Victims by Educational Level during 2013 - 2015

\begin{tabular}{|l|l|c|c|c|}
\hline Sr. no & Education Level & \multicolumn{3}{|c|}{ Percentage Share } \\
\hline & & $\mathbf{2 0 1 3}$ & $\mathbf{2 0 1 4}$ & $\mathbf{2 0 1 5}$ \\
\hline $\mathbf{1}$ & Professionals (MBA etc.) & $@$ & 0.3 & 0.4 \\
\hline $\mathbf{2}$ & Graduate \& above & 3.7 & 2.8 & 2.8 \\
\hline $\mathbf{3}$ & Diploma & 1.2 & 1.1 & 1.2 \\
\hline $\mathbf{4}$ & Higher Secondary Level & 10.3 & 11.0 & 11.9 \\
\hline $\mathbf{5}$ & Matriculate/Secondary Level & 20.5 & 20.5 & 21.7 \\
\hline $\mathbf{6}$ & Middle Level & 23.6 & 20.2 & 21.2 \\
\hline $\mathbf{7}$ & Primary Level & 22.1 & 19.0 & 19.7 \\
\hline $\mathbf{8}$ & No Education & 18.5 & 14.3 & 13.8 \\
\hline $\mathbf{9}$ & Status not known & $@$ & 10.8 & 7.4 \\
\hline $\mathbf{1 0}$ & Total & $\mathbf{1 0 0 . 0}$ & $\mathbf{1 0 0 . 0}$ & $\mathbf{1 0 0 . 0}$ \\
\hline
\end{tabular}

Table .2 Percentages of Suicide Victims by Educational Level during 2003 - 2005

\begin{tabular}{|l|l|c|c|c|}
\hline Sr. no & Educational Level & \multicolumn{3}{|c|}{ Percentage Share } \\
\hline & & $\mathbf{2 0 0 3}$ & $\mathbf{2 0 0 4}$ & $\mathbf{2 0 0 5}$ \\
\hline $\mathbf{1}$ & Post graduate \& above & 0.4 & 0.6 & 0.4 \\
\hline $\mathbf{2}$ & Graduate & 1.9 & 1.8 & 1.8 \\
\hline $\mathbf{3}$ & Diploma & 0.8 & 0.7 & 0.9 \\
\hline $\mathbf{4}$ & Higher Secondary & 7.5 & 7.6 & 7.4 \\
\hline $\mathbf{5}$ & Matriculate & 16.7 & 16.9 & 16.8 \\
\hline $\mathbf{6}$ & Middle(secondary) & 23.0 & 23.5 & 24.0 \\
\hline $\mathbf{7}$ & Primary & 26.2 & 25.2 & 25.8 \\
\hline $\mathbf{8}$ & No Education & 23.4 & 23.7 & 23.0 \\
\hline $\mathbf{9}$ & Total & $\mathbf{1 0 0 . 0}$ & $\mathbf{1 0 0 . 0}$ & $\mathbf{1 0 0 . 0}$ \\
\hline
\end{tabular}

***Source: National Crime Records Bureau (NCRB), India.

(c) The International Journal of Indian Psychology, ISSN 2348-5396 (e) | ISSN: 2349-3429 (p) | 145 
Psycho-Analytical Investigation of Stress among Students of Higher Technical Education in India: A Case Study

\section{ANNEXURE - II}

\section{Stress: Survey Questionnaire}

\begin{tabular}{|c|c|c|c|c|c|}
\hline Sr.no & Problem Statements & & Rest & onse: & \\
\hline & & $\mathbf{S}$ & $\mathbf{O}$ & A & $\mathbf{N}$ \\
\hline 1 & I find it difficult to relax. & & & & \\
\hline 2 & I suffer from sleeping problem. & & & & \\
\hline 3 & I find that I often get nervousness. & & & & \\
\hline 4 & I feel that life is meaningless. & & & & \\
\hline 5 & I feel depressed with challenging task. & & & & \\
\hline 6 & I feel anxious about my future prospect. & & & & \\
\hline 7 & I find myself quite upset quite upset at trivial things. & & & & \\
\hline 8 & I feel hangover at the end of the day. & & & & \\
\hline 9 & The preparation of exam makes me stressful. & & & & \\
\hline 10 & I find it easy to concentrate in the classroom. & & & & \\
\hline 11 & I get depressed if I face loss in anything. & & & & \\
\hline 12 & I did not find anything interesting about my life. & & & & \\
\hline 13 & I find that workload is affecting my health. & & & & \\
\hline 14 & I find it difficult to take certain decision quickly. & & & & \\
\hline 15 & I find that the world around me is problematic & & & & \\
\hline 16 & I do not experience any positive feeling at all. & & & & \\
\hline 17 & When I don’t get what I desire, I feel frustrated. & & & & \\
\hline 18 & I feel stressed before the declaration of the result. & & & & \\
\hline 19 & I feel frustrated when people misbehave with me. & & & & \\
\hline 20 & Studying or attending a class is really strain for me. & & & & \\
\hline 21 & I find it hard to cool me down after something upset me. & & & & \\
\hline 22 & I could not seem to get any enjoyment out of things I did. & & & & \\
\hline 23 & In my life, I am worried about my success and failure. & & & & \\
\hline 24 & I feel frustrated with passing remarks of my friends & & & & \\
\hline 25 & I find myself insecure when I think about my family background. & & & & \\
\hline 26 & I often compare myself with peers and feel myself stressed. & & & & \\
\hline 27 & I like to smoke, drink when I feel something is bothering me. & & & & \\
\hline 28 & I remain physically and mentally exhausted after class. & & & & \\
\hline 29 & I feel depressed regarding my environment and surroundings. & & & & \\
\hline 30 & I find it difficult to cope up friends, classmates and roommates. & & & & \\
\hline 31 & I find it difficult to adopt myself with changing environment. & & & & \\
\hline 32 & I feel frustrated to complete those assignments which I don’t like. & & & & \\
\hline 33 & I find it difficult to deal with the hassles and day to day problems. & & & & \\
\hline 34 & $\begin{array}{l}\text { I find myself disturbed when I am unable to control important } \\
\text { things in my life. }\end{array}$ & & & & \\
\hline 35 & $\begin{array}{l}\text { I feel horrified when the works pending and the deadlines are } \\
\text { approaching. }\end{array}$ & & & & \\
\hline
\end{tabular}

Note: $S$ - Sometimes, $\mathrm{O}$ - Often, A-Always, $\mathrm{N}$ - Never.

(c) The International Journal of Indian Psychology, ISSN 2348-5396 (e) | ISSN: 2349-3429 (p) | 146 
Psycho-Analytical Investigation of Stress among Students of Higher Technical Education in India: A Case Study

How to cite this article: Sharma S, Sinha S (2017), Psycho-Analytical Investigation of Stress among Students of Higher Technical Education in India: A Case Study, International Journal of Indian Psychology, Volume 4, Issue 2, No. 93, ISSN:2348-5396 (e), ISSN:2349-3429 (p), DIP:18.01.135/20170402, ISBN:978-1-365-78193-3 